\title{
Editorial: Cardiac Remodeling: New Insights in Physiological and Pathological Adaptations
}

\author{
Leonardo Roever ${ }^{1 *}$ and Antonio C. Palandri Chagas ${ }^{2,3}$ \\ ${ }^{1}$ Federal University of Uberlândia, Uberlândia, Brazil, ${ }^{2}$ Heart Institute (InCor), HCFMUSP University of São Paulo Medical \\ School, São Paulo, Brazil, ${ }^{3}$ Faculty of Medicine ABC, Santo André, Brazil
}

Keywords: cardiac remodeling, physiology, heart failure, fibrosis, inflammation

\section{Editorial on the Research Topic}

\section{Cardiac Remodeling: New Insights in Physiological and Pathological Adaptations}

\section{INTRODUCTION}

Cardiac remodeling (CR) is a complex process involving cardiac myocyte growth and death, vascular rarefaction, fibrosis, inflammation, and electrophysiological alterations (Burchfield et al., 2013; Xie et al., 2013). CR can be conceptualized as a set of cellular, cardiac and interstitial changes in the heart, manifested clinically by changes in the size, mass (hypertrophy and atrophy), geometry (wall thickness and heart shape) and function, in response to a given stimulus-it is one of the major responses of the heart to biomechanical stresses and pathological stimuli (Zornoff et al., 2009; Gajarsa and Kloner, 2011; Braunwald, 2013; Heusch et al., 2014; Sekaran et al., 2017). We can also detect the presence of scarred areas, fibrosis and inflammatory infiltrate.

The most common methods used to detect these CR are echocardiography, ventriculography,

\section{OPEN ACCESS}

Edited and reviewed by: Peter J. Reiser,

The Ohio State University Columbus, United States

*Correspondence:

Leonardo Roever leonardoroever@hotmail.com

Specialty section: This article was submitted to Striated Muscle Physiology, a section of the journal Frontiers in Physiology

Received: 24 July 2017 Accepted: 14 September 2017 Published: 26 September 2017

Citation:

Roever $L$ and Palandri Chagas AC (2017) Editorial: Cardiac Remodeling:

New Insights in Physiological and Pathological Adaptations.

Front. Physiol. 8:751

doi: 10.3389/fphys.2017.00751 tomography, magnetic resonance imaging, and most recently PET cardiac scans (Anand et al., 2002; Presotto et al., 2016). Biomarkers have been also used as indicators of CR, among them we can mention myosin heavy chain alterations (decrease of alpha and increase of beta-myosin), increase of caveolin, increase in neuronal nitric oxide synthase expression and increase of angiotensin converting enzyme, increase of alpha-actin, increase of galectin-3, increase of natriuretic peptides, decrease of GLUT-4 and increase Of GLUT-1, decrease of SERCA2a. Another feature is the substitution of the energetic preferential substrate of fatty acids for glucose (Swynghedauw, 2006; Eschalier et al., 2014; Liquori et al., 2014).

The aim of the present research topic was therefore to bring together key experiments, advances and new findings related to several aspects of CR.

Cardiac dysfunction is the main implication of the process of remodeling. It begins with genetic alterations in response to an insult to the heart, which is consequently manifested by cellular and molecular cardiac alterations, which result in progressive loss of ventricular function, initially asymptomatic and later with signs and symptoms characteristic of heart failure (Cohn et al., 2000; Azevedo et al., 2016). These stem from consequence of an excess of stimulation of the sympathetic system and the renin-angiotensin-aldosterone system which stimulates intracellular signaling pathways with a consequent increase in protein synthesis in myocytes and fibroblasts causing cellular hypertrophy and fibrosis, activation of growth factors, activation of metalloproteinases, hemodynamic overload by vasoconstriction and water retention, increase of oxidative stress and direct cytotoxic effect, leading to cell death by necrosis or apoptosis (Florea and Cohn, 2014; Sayer and Bhat, 2014). Another factor that is potentially responsible for altered cardiac function in the remodeling heart is the energy deficit, which results from the imbalance between supply and consumption of oxygen, including also the decrease in use of free fatty acids and increased 
use of glucose as a consequence of the reduction of $\beta$-oxidation, and abnormal accumulation of triglycerides and lipotoxicity may occur (Doenst et al., 2013; Santos et al., 2014; Nishida and Otsu, 2016).

Autophagy is an intracellular process in which defective or unnecessary cytoplasmic components are degraded by lysosomes which can result in accumulation of defective proteins, and in a process known as proteotoxicity (Tarone, 2014; Wang and Wang, 2015).

$\mathrm{CR}$ is also associated with oxidative stress due to an increase in the production of reactive species with the reduction of antioxidant defenses; this phenomenon can lead to several conditions, such as lipid peroxidation, changes in proteins responsible for calcium transit, activation of signaling pathways for hypertrophy, protein oxidation, DNA damage, cellular dysfunction, proliferation of fibroblasts, activation of metalloproteinases, stimulation of apoptosis, among others (Münzel et al., 2015).

Recent studies uncovered miR-22 as an important regulator for CR. miR-22 modulates the expression and function of genes involved in the hypertrophic response, sarcomere reorganization, and metabolic program shift during CR (Huang and Wang, 2014; Liu et al., 2015).

In CR there is evidence of changes in the calcium transport system, such as decrease of the L-channels and ryanodine receptors, as well as a decrease in the activity of calsequestrin and calmodulin kinase, and a reductionin in phospholamban phosphorylation. These alterations result in a decreased of supply of calcium during systole and increased calcium in diastole. These changes in the proteins in calcium transit may contribute to cardiac dysfunction (Luo and Anderson, 2013; Feridooni et al., 2015).

In addition, the collagen content plays a critical role in the maintenance of the architecture and cardiac function. In the $\mathrm{CR}$ process, there may be an imbalance between the synthesis and degradation of collagen with several deleterious effects, such as increased myocardial stiffness, diastolic dysfunction, worsening in coronary flow and the occurrence of malignant arrhythmias (Spinale et al., 2013; Deb and Ubil, 2014; Leask, 2015; López et al., 2015).

\section{REFERENCES}

Anand, I. S., Florea, V. G., Solomon, S. D., Konstam, M. A., and Udelson, J. E. (2002). Noninvasive assessment of left ventricular remodeling: concepts, techniques and implications for clinical trials. J. Card. Fail. 8(6 Suppl.), S452S464. doi: 10.1054/jcaf.2002.129286

Azevedo, P. S., Polegato, B. F., Minicucci, M. F., Paiva, S. A., and Zornoff, L. A. (2016). Cardiac remodeling: concepts, clinical impact, pathophysiological mechanismsand pharmacologic treatment. Arq Bras Cardiol. 106, 62-69. doi: 10.5935/abc. 20160005

Braunwald, E. (2013). Heart failure. JACC Heart Fail. 1, 1-20. doi: 10.1016/j.jchf.2012.10.002

Burchfield, J. S., Xie, M., and Hill, J. A. (2013). Pathological ventricular remodeling: mechanisms: part 1 of 2. Circulation 128, 388-400. doi: 10.1161/CIRCULATIONAHA.113.001878
The present research topic also provides readers with fundamental advancement in our understanding of the regulation of CR. Indeed, in an elegant study, Gibb et al. examined nocturnal/diurnal behavior, treadmill exercise compliance, and systemic as well as cardiac-specific exercise adaptations in two commonly used mouse strains C57BL/6J, and $\mathrm{FVB} / \mathrm{NJ}$ mice. FVB/NJ strain is a useful and robust mouse model for examining cardiac adaptations to treadmill exercise and that treadmill training during daytime hours does not negatively affect exercise compliance or capacity. Finally, they provide new insights to demonstrate that $\mathrm{FVB} / \mathrm{NJ}$ mice are a suitable and robust model for understanding the mechanisms underlying cardiac adaptations to exercise (Gibb et al.).

In other article, Ruiz-Hurtado et al. investigated whether mild ( $20 \%$ food intake reduction) and short-term (2-weeks) caloric restriction prevented the obese cardiomyopathy phenotype and improved the metabolic profile of young (14 weeks of age) genetically obese Zucker fa/fa rats. The results suggest that with mild and short-term caloric restriction prevented an obesityinduced cardiomyopathy phenotype in young obese fa/fa rats independently of the cardiac metabolic profile.

Bai et al. contributed a very interesting review paper focused on the mechanisms underlying the emergence of post-acidosis arrhythmia at the tissue level, altered source-sink interactions and electrical heterogeneity due to acidosis-induced cellular electrophysiological alterations which may increase susceptibility to post-acidosis ventricular arrhythmias.

Due to the diversity and high quality of the articles compiled here, we hope that this can offer new ideas and research projects for new advances in the field.

\section{AUTHOR CONTRIBUTIONS}

LR: Substantial contributions to the conception or design of the work; or the acquisition, analysis, or interpretation of data for the work; Drafting the work or revising it critically for important intellectual content; Final approval of the version to be published. AP: Substantial contributions to the conception or design of the work; or the acquisition, analysis, or interpretation of data for the work; Drafting the work or revising it critically for important intellectual content; Final approval of the version to be published.

Cohn, J. N., Ferrari, R., and Sharpe, N. (2000). Cardiac remodeling-concepts and clinical implications: a consensus paper from an international forum on cardiac remodeling. Behalf of an International Forum on Cardiac Remodeling. J. Am. Coll. Cardiol. 35, 569-582. doi: 10.1016/S0735-1097(99)00630-0

Deb, A., and Ubil, E. (2014). Cardiac fibroblast in development and wound healing. J. Mol. Cell. Cardiol. 70, 47-55. doi: 10.1016/j.yjmcc.2014. 02.017

Doenst, T., Nguyen, T. D., and Abel, E. D. (2013). Cardiac metabolism in heart failure: implications beyond ATP production. Circ Res. 113, 709-724. doi: 10.1161/CIRCRESAHA.113.300376

Eschalier, R., Rossignol, P., Kearney-Schwartz, A., Adamopoulos, C., Karatzidou, K., Fay, R., et al. (2014). Features of cardiac remodeling, associated with blood pressure and fibrosis biomarkers, are frequent in subjects with abdominal obesity. Hypertension 63, 740-746. doi: 10.1161/HYPERTENSIONAHA.113.02419 
Feridooni, H. A., Dibb, K. M., and Howlett, S. E. (2015). How cardiomyocyte excitation, calcium release and contraction become altered with age. J. Mol. Cell. Cardiol. 83, 62-72. doi: 10.1016/j.yjmcc.2014.12.004

Florea, V. G., and Cohn, J. N. (2014). The autonomic nervous system and heart failure. Circ Res. 114, 1815-1826. doi: 10.1161/CIRCRESAHA.114.302589

Gajarsa, J. J., and Kloner, R. A. (2011). Left ventricular remodeling in the postinfarction heart: a review of cellular, molecular mechanisms, and therapeutic modalities. Heart Fail Rev. 16, 13-21. doi: 10.1007/s10741-010-9181-7

Heusch, G., Libby, P., Gersh, B., Yellon, D., Lopaschuk, G., and Opie, L. (2014). Cardiovascular remodelling in coronary artery disease and heart failure. Lancet 383, 1933-1943. doi: 10.1016/S0140-6736(14)60107-0

Huang, Z. P., and Wang, D. Z. (2014). miR-22 in cardiac remodeling and disease. Trends Cardiovasc Med. 24, 267-272. doi: 10.1016/j.tcm.2014.07.005

Leask, A. (2015). Getting to the heart of the matter: new insights into cardiac fibrosis. Circ Res. 116, 1269-1276. doi: 10.1161/CIRCRESAHA.116.305381

Liquori, M. E., Christenson, R. H., Collinson, P. O., and Defilippi, C. R. (2014). Cardiac biomarkers in heart failure. Clin. Biochem. 47, 327-337. doi: 10.1016/j.clinbiochem.2014.01.032

Liu, X., Xiao, J., Zhu, H., Wei, X., Platt, C., Damilano, F., et al. (2015). miR-222 is necessary for exercise-induced cardiac growth and protects against pathological cardiac remodeling. Cell Metab. 21, 584-595. doi: 10.1016/j.cmet.2015. 02.014

López, B., González, A., Ravassa, S., Beaumont, J., Moreno, M. U., San José, G., et al. (2015). Circulating biomarkers of myocardial fibrosis: the need for a reappraisal. J. Am. Coll. Cardiol. 65, 2449-2456. doi: 10.1016/j.jacc.2015.04.026

Luo, M., and Anderson, M. E. (2013). Mechanisms of altered $\mathrm{Ca}^{2+}$ handling in heart failure. Circ Res. 113, 690-708.

Münzel, T., Gori, T., Keaney, Jr, J. F., Maack, C., and Daiber, A. (2015). Pathophysiological role of oxidative stress in systolic and diastolic heart failure and its therapeutic implications. Eur. Heart J. 36, 2555-2564. doi: 10.1093/eurheartj/ehv305

Nishida, K., and Otsu, K. (2016). Autophagy during cardiac remodeling. J. Mol. Cell. Cardiol. 95, 11-18. doi: 10.1016/j.yjmcc.2015.12.003

Presotto, L., Busnardo, E., Gianolli, L., and Bettinardi, V. (2016). An update on technical and methodological aspects for cardiac PET applications. Q. J. Nucl. Med. Mol. Imaging 60, 285-307.
Santos, P. P., Oliveira, F., Ferreira, V. C., Polegato, B. F., Roscani, M. G., Fernandes, A. A., et al. (2014). The role of lipotoxicity in smoke cardiomyopathy. PLoS ONE 9:e113739. doi: 10.1371/journal.pone.0113739

Sayer, G., and Bhat, G. (2014). The renin-angiotensin-aldosterone system and heart failure. Cardiol. Clin. 32, 21-32. doi: 10.1016/j.ccl.2013.09.002

Sekaran, N. K., Crowley, A. L., de Souza, F. R., Resende, E. S., and Rao, S. V. (2017). The Role for Cardiovascular Remodeling in Cardiovascular Outcomes. Curr. Atheroscl. Rep. 19:23. doi: 10.1007/s11883-017-0656-Z

Spinale, F. G., Janicki, J. S., and Zile, M. R. (2013). Membraneassociated matrix proteolysis and heart failure. Circ. Res. 112, 195-208. doi: 10.1161/CIRCRESAHA.112.266882

Swynghedauw, B. (2006). Phenotypic plasticity of adult myocardium: molecular mechanisms. J. Exp. Biol. 209(Pt. 12), 2320-2327. doi: 10.1242/jeb.02084

Tarone, G. (2014). Brancaccio M Keep your heart in shape: molecular chaperone networks for treating heart disease. Cardiovasc. Res. 102:346. doi: $10.1093 / \mathrm{cvr} / \mathrm{cvu} 049$

Wang, C., and Wang, X. (2015). The interplay between autophagy and the ubiquitinproteasome system in cardiac proteotoxicity. Biochim. Biophys. Acta 1852, 188-194. doi: 10.1016/j.bbadis.2014.07.028

Xie, M., Burchfield, J. S., and Hill, J. A. (2013). Pathological ventricular remodeling: therapies: part 2 of 2 . Circulation 128, 1021-1030. doi: 10.1161/CIRCULATIONAHA.113.001879

Zornoff, L. A., Paiva, S. A., Duarte, D. R., and Spadaro, J. (2009). Ventricular remodeling after myocardial infarction: concepts and clinical implications. Arq Bras Cardiol. 92, 157-164. doi: 10.1590/S0066-782X2009000200013

Conflict of Interest Statement: The authors declare that the research was conducted in the absence of any commercial or financial relationships that could be construed as a potential conflict of interest.

Copyright (c) 2017 Roever and Palandri Chagas. This is an open-access article distributed under the terms of the Creative Commons Attribution License (CC BY). The use, distribution or reproduction in other forums is permitted, provided the original author(s) or licensor are credited and that the original publication in this journal is cited, in accordance with accepted academic practice. No use, distribution or reproduction is permitted which does not comply with these terms. 